Macedonian Pharmaceutical Bulletin, 66 (Suppl 1) 183 - 184 (2020)

Online ISSN $1857-8969$

UDC: 615.253:[615.451.2.074:543.544.5.068.7

DOI: 10.33320/maced.pharm.bull.2020.66.03.091

Short communication

\title{
Develompent and validation of a RP-HPLC method for simulatenous determination of terbutaline sulfate, guaifenesin, bromhexine hydrochloride and sodium benzoate in a syrup formulation
}

\author{
Marjan Piponski*, Tanja Bakovska Stoimenova, Kristina Grnacharoska, \\ Martina Miloshevska, Irena Slaveska Spirevska, Emilija Pockova, \\ Elena Petrovska, Marjan Velkovski
}

Replek Farm Ltd., Kozle 188, 1000 Skopje, N. Macedonia

\section{Introduction}

Terbutaline sulfate is a selective beta- 2 adrenergic agonist used as a bronchodilator, used to treat wheezing and shortness of breath from lung problems (e.g. asthma, chronic obstructive pulmonary disease, bronchitis and emphysema).

Bromhexine hydrochloride is mucolytic, which helps clear chest congestion, thus contributes to a secretomotoric effect. It also has antioxidant properties.

Guaifenesin is an expectorant, working by thinning and loosening mucus in the airways, cleaning congestion, and making breathing easier. It is used to treat coughs and congestion caused by the common cold, bronchitis, and other breathing illnesses (McCrory et al., 2013).

Sodium benzoate is used as a preservative in the syrup formulation.

There are a number of methods available for determination of terbutaline sulfate, bromhexine hydrochloride and guaifenesin individually $(\mathrm{Ph}$. Eur., BP, USP), but only a few methods for simultaneous determination of a combination of them in a syrup formulation.
The aim of our work was to develop and validate a simple and rapid reversed-phase high performance liquid chromatography (RP-HPLC) method for simultaneous estimation of the active substances, terbutaline sulfate, guaifenesin, bomhexine hydrochloride and the preservative sodium benzoate, in a cough syrup formulation.

\section{Materials and methods}

The reagents that have been used are: ammonium dihydrogen phosphate $\left(\mathrm{NH}_{4} \mathrm{H}_{2} \mathrm{PO}_{4}\right)$ and $85 \%$ o-phosphoric acid $\left(\mathrm{H}_{3} \mathrm{PO}_{4}\right)$ purchased from Sigma Aldrich, USA, methanol and acetonitrile procured from Merck, Darmstadt, Germany, and the demineralized water was 'in house' prepared with conductivity of $0.05 \mu \mathrm{S} / \mathrm{cm}$. The terbulatine sulfate reference standard, bromhexine $\mathrm{HCl} \mathrm{CRM}$, guaifenesin CRM and sodium benzoate analytical standard, were purchased from Sigma-Aldrich, USA, and the syrup formulation was obtained from Replek Farm Ltd., Skopje, N. Macedonia. The syringe filters Nylon and RC, $0,45 \mu \mathrm{m}$, were purchased from Agilent Technologies (USA).

\footnotetext{
*piponski99@gmail.com
} 
Instruments that have been used are: UPLC Shimadzu Nexera XR system with LPG quaternary pump with degasser, autosempler, controller and PDA detector and column oven, controlled by Lab Solutions software, version 5.97.; analytical balance Mettler Toledo AG285; pH-metter Metrohm 827 pH Lab; and IKA orbital shaker KS 260 basic.

The separation was accomplished using Inertsil RP8 $250 \mathrm{~mm} \times 4.6 \mathrm{~mm}, 5 \mu \mathrm{m}$ column from GL Sciences, Tokyo, Japan.

\section{Results and discussion}

The chromatographic separation of all three active substances and the preservative (all with significant differences in their concentrations, polarities, solubility, UV absorbing spectra and molar absorption coefficients) was carried out on a GL Sciences Inertsil RP8 $250 \mathrm{~mm} \times 4.6 \mathrm{~mm}, 5 \mu \mathrm{m}$ column, under isocratic conditions, with mobile phase consisting of $20 \% \mathrm{v} / \mathrm{v}$ methanol, $20 \% \mathrm{v} / \mathrm{v}$ acetonitrile and $60 \% v / v 20 \mathrm{mM} \mathrm{NH} \mathrm{H}_{2} \mathrm{PO}_{4} \mathrm{pH} 2.5$, with flow rate was $1.2 \mathrm{~mL} / \mathrm{min}$, detection wavelength at $220 \mathrm{~nm}$, column temperature of $30^{\circ} \mathrm{C}$ and injection volume of $5 \mu \mathrm{L}$.

The isocratic elution of the analytes was achieved in $12 \mathrm{~min}$, with retention time of terbutaline sulfate, guaifenesin, sodium benzoate and bromhexine $\mathrm{HCl}$ on 2.3, 4.6, 7.6 and 9.7 minutes, respectively. All four chromatographic peaks are well separated between each other, to the baseline. The obtained values for number of theoretical chromatographic plates for terbutaline sulfate, guaifenesin, sodium benzoate and bromhexine $\mathrm{HCl}$, were 4025, 10201, 12641 and 10151, respectively.

The established method was validated according to the International Conference on Harmonization (ICH) Q2(R1) guideline for validation of analytical procedures. During selectivity testing, no interference from the formulation excipients was observed. The linerity of the method was proved in five concentration levels, for each substance of interest and the following results were obtained by regression analysis: correlation coefficient $>0.9990$ and relative standard deviation of the response factors for each concentration level $<2 \%$, in all cases. The precision of the system and of the method were also evaluated and the obtained relative standard deviation of the responses was less or equal to $2 \%$, in both cases, for each substance. Accurancy of the method was studied by recovery investigation. The obtained recovery values were within the range of $100 \pm 2 \%$, for each substance. The robustness testing of the method, showed that the obtained results are not adversely affected by small variations in method parametars.

\section{Conclusion}

The developed RP-HPLC method enables simultaneous, fast and accurate determination of the three active substances, terbulatine sulfate, guaifenesin and bromhexine $\mathrm{HCl}$, and the preservative, sodium benzoate, all with different physico-chemical properties, in syrup formulation. The method was validated and proved as suitable for its intended use. The proposed method, using simple sample preparation and low cost reagents, provides reproducible quantification of all substances of interest and can be successfully used for routine analysis or cough syrups containing this combination of active substances.

\section{References}

Assessment and management of chronic cough. Comparative effectiveness review No. 100, Rockville: Agency for Healthcare Research and Quality.

British Pharmacopoeia, 2018. British Pharmacopoeia Commission - The Stationery Office: London

European Pharmacopoeia, $9^{\text {th }}$ ed., 2016-2017. European Directorate for the Quality of Medicines \& Healthcare - Council of Europe: Strasbourg.

International Conference on Harmonization, 2005. Validation of analytical procedures: Text and methodology Q2(R1). ICH, Geneva, Switzerland.

McCrory, D.C., Coeytaux, R.R., Yancy, W.S. Jr., Schmit, K.M., Kemper, A.R., Goode, A., Hasselblad, V., Heidenfelder, B.L., Irvine, R.J., Musty, M.D., Gray, R., Sanders, G.D., 2013. Assessment and management of chronic cough. Comparative effectiveness review No. 100, Rockville: Agency for Healthcare Research and Quality.

The United States Pharmacopeia/The National Formulary (USP 40-NF 35), 2017. The United States Pharmacopeia Convention: Rockville.

Maced. Pharm. Bull. 66 (Suppl 1) 183 - 184 (2020) 